\title{
BMJ Assessment of simple risk markers for Open early mortality among HIV-infected patients in Guinea-Bissau: a cohort study
}

\author{
Inés Oliveira, ${ }^{1,2}$ Andreas Andersen, ${ }^{1}$ Alcino Furtado, ${ }^{1}$ Candida Medina, ${ }^{3}$ \\ David da Silva, ${ }^{3}$ Zacarias J da Silva, ${ }^{1,4}$ Peter Aaby, ${ }^{1,5}$ Alex Lund Laursen, ${ }^{6}$ \\ Christian Wejse, ${ }^{6,7}$ Jesper Eugen-Olsen, ${ }^{2}$ for the Bissau HIV cohort study group
}

To cite: Oliveira I, Andersen A, Furtado A, et al. Assessment of simple risk markers for early mortality among HIV-infected patients in Guinea-Bissau: a cohort study. BMJ Open 2012;2:e01587.

doi:10.1136/bmjopen-2012001587

- Prepublication history and additional material for this paper are available online. To view these files please visit the journal online (http://dx.doi.org/10.1136/ bmjopen-2012-001587).

Received 31 May 2012 Accepted 26 August 2012

This final article is available for use under the terms of the Creative Commons Attribution Non-Commercial 2.0 Licence; see http://bmjopen.bmj.com

For numbered affiliations see end of article.

\section{Correspondence to}

Dr Jesper Eugen-Olsen; jespereugenolsen@gmail.com

\section{ABSTRACT}

Background: Decisions about when to start an antiretroviral therapy (ART) are normally based on CD4 cell counts and viral load (VL). However, these measurements require equipment beyond the capacity of most laboratories in low-income and middle-income settings. Thus, there is an urgent need to identify and test simple markers to guide the optimal time for starting and for monitoring the effect of ART in developing countries.

Objectives: (1) To evaluate anthropometric measurements and measurement of plasma-soluble form of the urokinase plasminogen activator receptor (suPAR) levels as potential risk factors for early mortality among HIV-infected patients; (2) to assess whether these markers could help identify patients to whom ART should be prioritised and (3) to determine if these markers may add information to CD4 cell count when VL is not available.

Design: An observational study.

Setting: The largest ART centre in Bissau, GuineaBissau.

Participants: 1083 ART-naïve HIV-infected patients.

Outcome measures: Associations between baseline anthropometric measurements, CD4 cell counts, plasma suPAR levels and survival were examined using Cox proportional hazards models.

Results: Low body mass index (BMI $\left.\leq 18.5 \mathrm{~kg} / \mathrm{m}^{2}\right)$, low mid-upper-arm-circumference (MUAC $\leq 250 \mathrm{~mm}$ ), low CD4 cell count $(\leq 350$ cells/ $\mu$ l) and high suPAR plasma levels $(>5.3 \mathrm{ng} / \mathrm{ml})$ were independent predictors of death. Furthermore, mortality among patients with low CD4 cell count, low MUAC or low BMI was concentrated in the highest suPAR quartile.

Conclusions: Irrespective of ART initiation and baseline CD4 count, MUAC and suPAR plasma levels were independent predictors of early mortality in this urban cohort. These markers could be useful in identifying patients at the highest risk of short-term mortality and may aid triage for ART when CD4 cell count is not available or when there is shortness of antiretroviral drugs.

\section{ARTICLE SUMMARY}

Article focus

- The measurement of CD4 cell counts and viral load require equipment beyond the capacity of most laboratories in low-income and middleincome countries.

- There is an urgent need to test simple markers to guide the optimal time for starting antiretroviral therapy (ART) in these settings.

- The objectives of the study were: (1) to evaluate anthropometric measurements and a soluble form of the urokinase plasminogen activator receptor (suPAR) levels as potential risk factors for early mortality in an urban cohort of HIV-infected patients in Bissau and (2) to assess whether these markers may add information to CD4 cell count and aid in selection of patients most in need of ART.

Key messages

- A low body mass index, low middle-upper-armcircumference (MUAC), low CD4 cell count and high suPAR plasma levels were independent predictors of early mortality in patients enrolled in this cohort.

- Mortality among patients with a low CD4 cell count, low MUAC or low BMI was concentrated in the highest suPAR quartile.

- MUAC and suPAR could be useful in identifying patients at the highest risk of short-term mortality and may aid triage for ART when CD4 cell count is not available or when there is shortness of antiretroviral drugs.

\section{INTRODUCTION}

Since its introduction in the mid-1990s, antiretroviral therapy (ART) has reduced the morbidity and mortality of HIV-infected patients worldwide. ${ }^{1-3}$ Nevertheless, despite progress, access to these lifesaving drugs remains limited where the need is the 


\section{ARTICLE SUMMARY}

Strengths and limitations of this study

- Data presented could help health providers to identify patients with the highest risk of short-term mortality and to prioritise treatment among eligible patients in a context of poor healthcare infrastructure.

- There are several limitations to this study. First, information on all four investigated risk factors (CD4, suPAR, BMI and MUAC) was only available in $58 \%(628 / 1083)$ of our population. Second, WHO-stage, pregnancy status and comorbidities presented at the time of inclusion were not recorded in the database. Third, contact information for some patients was not sufficient to allow active tracing in case of missed appointments. Thus, it is likely that patients lost to follow-up may include unascertained deaths and that the effects of the risk factors are underestimated in our work.

greatest, especially in subSaharan Africa. ${ }^{4}$ Treating HIV patients in low-income and middle-income countries (LMICs) means working in a context of poor healthcare infrastructure and limited human resources. ${ }^{5}$ To provide sustainable access to ART to these regions, models of care must be adapted to the realities of the developing world. ${ }^{6}$ Simplification and decentralisation of treatment are essential components of a successful strategy for scaling-up ART. ${ }^{6}$ In this concept of simplification the whole process of providing antiretroviral (ARV) drugs should be covered, starting with setting simple inclusion criteria for an ART. In industrialised countries, decisions about when to start combined ART are based on CD4 T-cell (CD4) cell count and plasma viral load (VL), two of the strongest predictors of survival in HIV patients. ${ }^{7} 8$ However, these measurements require equipment beyond the capacity of most laboratories in LMICs. ${ }^{9} 10$ Until accessible and affordable means of measuring CD4 cell count and VL become widely available, there is an urgent need to develop and test simple markers or clinical criteria to guide the optimal time for starting ART in the developing world. ${ }^{11}$ Previous studies have shown that HIV patients with low haemoglobin level, low body mass index (BMI) ${ }^{12-14}$ advanced WHO-clinical stage, high-plasma levels of a soluble form of the urokinase plasminogen activator receptor (suPAR) ${ }^{15}$ or with detectable cryptococcal antigenaemia ${ }^{16}{ }^{17}$ are at a higher risk of dying during the first months of follow-up. ${ }^{18}$

Weight loss is the only nutritional criterion used in the WHO classification system ${ }^{19}$ but has the disadvantage that it is not available at the first consultations because most patients do not know their normal weight. ${ }^{13}$ BMI (weight in kilograms divided by height in metres squared) has been confirmed to be an easy-to-measure alternative to weight loss to predict survival in both, developed ${ }^{14}$ and developing countries. ${ }^{12} 13{ }^{20}$ Different BMI thresholds have been proposed to identify patients with a poor survival; ${ }^{12}{ }^{13}$ however, this indicator has the limitation that it cannot be used in patients too weak to stand. Middle-upper-arm circumference (MUAC) can be easily measured on all patients, including bedridden ones, and does not require further calculations. Nevertheless, studies assessing this marker in HIV adults in LMICs are scarce.

SuPAR is a risk biomarker protein that reflects the level of immune activation and inflammation. ${ }^{21}$ It is known that immune activation plays an important role in the pathogenesis of HIV infection. ${ }^{22-25}$ High blood levels of suPAR have been associated with poor clinical outcome and independently predict mortality in non-ART-treated HIV infected patients. ${ }^{15} \quad 24 \quad 26 \quad 27$ Furthermore, plasma concentrations of suPAR can be measured using a simple ELISA or lateral flow quick tests and thus require less-sophisticated laboratory infrastructure than that needed for routine measurements of CD4 count or plasma VL.

The rollout of ART in Guinea-Bissau started in 2005. All treatments are free of charge in the country, however during the later years frequent shortages of ARV drugs and reagents for $\mathrm{CD} 4$ count equipment, have hampered the management of HIV patients in the country and has enforced clinicians to prioritise treatment among eligible patients. ${ }^{28}$

The objectives of the present study were: (1) to evaluate anthropometric measurements, other than weight loss and measurement of suPAR levels as potential risk factors for early mortality in an urban cohort of HIV-1, HIV-2 and HIV-double-infected patients; (2) to examine whether these markers could help in identifying patients to whom ART should be prioritised when CD4 cell count is not available or in situations of shortness of ARV drugs and (3) to assess whether these markers may add information to CD4 cell count and aid in selection of patients most in need of ART among eligible patients when VL is not available.

\section{METHODS \\ Setting}

The Republic of Guinea-Bissau has an estimated population of 1600000 inhabitants and an economy based primarily on farming and fishing activities. More than 2/3 of the population lives below the poverty line. ${ }^{29}$ Ranking 176 out of 187 countries on the United Nations Human Development Index 2011, it is one of the poorest countries in the world. ${ }^{30}$ The HIV National Programme was implemented by the Ministry of Health (MINSAP) in 2005. The combined ART is free of charge in the country, the cost being fully subsidised by the Global Fund to Fight AIDS, Tuberculosis (TB) and Malaria, the Brazilian Government and other international partners. ${ }^{31}$ At the beginning of 2010, there were 26 ART centres in Guinea-Bissau, with more than 7000 patients on a follow-up and 2764 patients on treatment. ${ }^{32}$

\section{Study population}

The National Simão Mendes Hospital (NSMH), located in the capital, Bissau, is the reference hospital in the 
country. The outpatient ART centre of NSMH (ART-NSMH) is the largest ART centre in Guinea-Bissau in terms of patients on a follow-up. At the end of 2009, one-third of the patients on ART in the country were followed in this centre. ${ }^{32}$

The present study population includes all HIV-infected patients, aged 15 years and older, included in the Bissau-HIV cohort between July 2007 and December 2009. The aims and characteristics of the cohort have been described elsewhere. ${ }^{32}$ During the study period, National ART guidelines were based on the 2002 WHO recommendations. ${ }^{33}$ The standard first-line ART for HIV-1 patients comprised Zidovudine (AZT), Lamivudine (3TC) plus a non-nucleoside reverse transcriptase inhibitor (NNRTI) (Efavirenz (EFV) or Nevirapine (NVP)). Regarding HIV-2 and dually infected patients (HIV-1+2), the standard first-line comprised AZT, 3TC plus Indinavir/ritonavir (IND/rtv). ABC was offered as an alternative to the protease inhibitor (PI) when CD4 count was over the 200 cells/ $\mu$ l threshold. Stavudine $(\mathrm{d} 4 \mathrm{t})$ was the alternative to AZT for patients with anaemia (haemoglobin $\leq 8 \mathrm{~g} / \mathrm{dl}$ ) in all groups.

\section{Study description}

Information about the study was provided by experienced assistants at the time of inclusion in the Bissau-HIV cohort. After signing the consent form, an interview was carried out using a structured questionnaire and a venous blood sample of $8 \mathrm{ml}$ was collected in a Microtainer evacuated blood collection system with additives (K2EK2EDTA-Greiner bio-one, USA). As part of the inclusion, height (without shoes) and weight were measured for all patients able to stand. MUAC was measured on the left arm at the mid-point between the tip of the shoulder and the tip of the elbow using a TALC insertion tape (Teaching Aids at Low Cost, St. Albans, England).

\section{Laboratory methods \\ HIV testing}

HIV screening was carried out using a rapid test (Determine HIV-1/2 assay (Abbott Laboratories, Abbott Park, Illinois, USA). Patients testing positive were sent to the National Public Health Laboratory (NPHL), the reference laboratory in the country, for confirmation and discrimination. Capillus HIV-1/HIV-2 (Cambridge Diagnostics, Galway, Ireland) as well as Immunocomb II HIV-1\&2 Bispot (Orgenics, Yavne, Israel) were the tests used. SD Bioline (HIV 1+2 SD Bioline HIV 1/2 3.0 rapid test, Standard Diagnostics, Inc, Korea) was used in the clinic when quick medical decisions were needed or when there was a rupture of stock of reagents in the NPHL.

\section{CD4 cell count}

CD4 cell counts were obtained using the Partec CyFlow SL_3 (Cyflow SL, Partec, Munster, Germany) at the NPHL.

\section{Plasma suPAR measurement}

Plasma samples were stored at $-20^{\circ} \mathrm{C}$ at the NLPH and sent to Denmark and measured using the suPARnostic ELISA kit (ViroGates, Copenhagen, Denmark) according to the manufacturer's instructions. One kit served to process 82 samples in $<2 \mathrm{~h}$. The interassay variation of a control sample run on all plates was $12 \%$.

\section{Statistical methods and analysis}

Data were entered into an Access database by trained data entry staff and the analysis was carried out using STATA V.11. Patients who did not attend the clinic for two consecutive months (missed two scheduled visits) and for whom vital status was unknown were registered as lost to follow-up (LTFU). ${ }^{34}$ Patients LTFU were contacted by the staff whenever a telephone number was available. In case a patient died the time of death was obtained from hospital records or relatives.

Follow-up was restricted to 6 months. Person-time was calculated from inclusion date until death, permanent deferral or the end of the study, whichever came first. Patients LTFU and transferred patients were included in the survival analysis until the last day they were known to be alive.

We estimated the overall incidence of mortality and studied risk factors associated with death using Cox proportional hazard models using age as the underlying time variable. Baseline explanatory variables were age, sex, HIV type, BMI, MUAC, suPAR plasma levels and baseline CD4 cell count (with two cut-off points tested: $\leq 200$ and $\leq 350$ cells $/ \mu \mathrm{l}$ ). A normal BMI was defined as $18.5-24.9 \mathrm{~kg} / \mathrm{m}^{2}$ and malnutrition was defined as a BMI $<18.5 \mathrm{~kg} / \mathrm{m}^{2}$ according to the United Nations FAO criteria. ${ }^{35}$ Low MUAC was defined as MUAC $\leq 250 \mathrm{~mm}$.

A forward selection procedure for selecting predictive markers with $\mathrm{p}<0.05$ was used to create a multivariate Cox model. Mortality according to $\mathrm{CD} 4 \leq 350$ cells $/ \mu \mathrm{l}$, $\mathrm{BMI} \leq 18.5 \mathrm{~kg} / \mathrm{m}^{2}$ and MUAC $\leq 250 \mathrm{~mm}$ were further assessed by Kaplan-Meier curves. Receiver operating characteristic (ROC) curves were applied to assess the prognostic capacity of each marker and the area under the curve (AUC) was presented. The Youden Index ${ }^{36}$ was used to calculate the cut-off yielding the maximal joint sensitivity and specificity. Measurements of MUAC, BMI and especially suPAR were not available for all patients (see online Supplementary data file 1 ). Some patients were too sick to stand to measure height and weight. Consequently, mortality was very high in the group with the BMI information missing. The predictive capacity of BMI has therefore been penalised in the analyses where these missing observations have been excluded. Many suPAR measurements were missing because samples were lost during transportation from Guinea Bissau to Denmark.

\section{Populations described}

- Entire cohort: ART-naïve patients with CD4 cell count available at inclusion and seen at least once after recruitment $(\mathrm{n}=1083)$. 
- Population A: Patients included with MUAC, BMI and CD4 available $(n=1,054)$. Out of them, 1049 contributed with pre-ART risk time.

- Population B: Patients included with MUAC, BMI, CD4 and suPAR available $(\mathrm{n}=628)$. Out of them, 625 contributed with pre-ART risk time.

\section{Ethical considerations}

The study was approved by the National Ethics Committee of Guinea-Bissau. All participants were counselled and provided with informed written consent before their inclusion in the study.

\section{RESULTS}

\section{Study population}

Between July 2007 and December 2009, 1562 adults were enrolled in the Bissau-HIV cohort. A total of 1402 patients $(90 \%)$ were seen at least once after recruitment. Those who were on ART at enrolment $(n=228)$ or without CD4 cell count available at inclusion $(n=91)$ were excluded from analysis. Among the remaining 1083 ART-naive patients $(70 \%$ women), the median age was 35 years (IQR 29 to 45), women being younger than men (34 vs 40 years, $\mathrm{p}=<0.001$ ). The majority of patients were HIV-1-seropositive (67\%), whereas $20 \%$ were HIV-2-seropositive and $13 \%$ tested positive for both viruses. After screening, 567 patients (52\%) started ART within the first 6 months of follow-up.

\section{Baseline CD4 cell count, BMI, MUAC and suPAR}

The median baseline CD4 cell count for the entire cohort was 192 cells/ $\mu \mathrm{l}$ (IQR 82-353, n=1083). There were slight differences in CD4 cell count according to HIV types; HIV-1 patients had the lowest CD4 count with a median of 176 cells/ $\mu$ l (IQR 77-334) followed by double-infected patients (median 190 cells/ $\mu$ (IQR 91-337) and HIV-2-infected patients (median 219 cells/ $\mu$ l (IQR $110-439), \mathrm{p}<0.001)$. Patients who died had a significantly lower baseline CD4 counts than those who survived the 6-month follow-up period (median 67 vs 208 cells/ $\mu$ l, respectively).

Regarding the anthropometric measurements, median BMI at inclusion was $19.7 \mathrm{~kg} / \mathrm{m}^{2}$ (IQR 17.4-22.4, $\mathrm{n}=1057$ ) and $256 \mathrm{~mm}$ (IQR 232-286, $\mathrm{n}=1064$ ) for MUAC. Both measurements were lower for patients who died during follow-up (Median BMI $17.5 \mathrm{vs} 20 \mathrm{~kg} / \mathrm{m}^{2}$ in survivors, $\mathrm{p}<0.001$, and median MUAC $230 \mathrm{~mm}$ in patients who died vs $262 \mathrm{~mm}$ in survivors, $\mathrm{p}<0.001)$. The baseline median of suPAR plasma level was $3.5 \mathrm{ng} / \mathrm{ml}$ (IQR 2.6-5.3, N=646), being $3.4 \mathrm{ng} / \mathrm{ml}$ for patients who survived vs $7.6 \mathrm{ng} / \mathrm{ml}$ in patients who died, $\mathrm{p}<0.001$. There were no statistically significant differences in BMI, MUAC or suPAR according to sex or HIV type. Baseline characteristics of the cohort are summarised in the online supplementary data file 1 .

The parameters of organ function creatinine, Aspartate aminotransferase (AST) and Alanine aminotransferase
(ALT) were measured at inclusion. The median concentration was $0.8 \mathrm{mg} / \mathrm{dl}(\mathrm{IQR} 0.6-1)$ for creatinine $(\mathrm{n}=534)$, $30 \mathrm{UI} / \mathrm{L}(\mathrm{IQR}$ 20.3-43) for AST $(\mathrm{n}=436)$ and $17 \mathrm{UI} / \mathrm{L}$ (IQR 10-27.3) for ALT $(n=430)$. The correlation with suPAR was 0.18 for creatinine $(p=0.002), 0.15$ for AST $(\mathrm{p}=0.011)$ and 0.12 for ALT $(\mathrm{p}=0.04)$.

\section{Overall risk factors for mortality}

During follow-up there were 120 deaths, 178 were LTFU and 23 patients were transferred to other centres (study profile of the study available in online supplementary data file 2). Forty-one patients returned to the clinic after being considered LTFU. With 426 person-years of observation (PYO) in the study, the overall death rate was 28 per 100 PYO.

Including the time before and after the initiation of treatment, the overall mortality HR was 4.98 (3.05 to 8.15) for patients with $\mathrm{CD} 4 \leq 200$ cells/ $\mu$ land 4.73 (2.29 to 9.75) for patients with $\mathrm{CD} 4 \leq 350$ cells/ $\mu$ l. The HR was 2.66 (1.77 to 3.99) for patients with $\mathrm{BMI} \leq 18.5 \mathrm{~kg} / \mathrm{m}^{2} \quad(\mathrm{n}=1056), 4.70$ (2.97 to 7.45) for patients with MUAC $\leq 250 \mathrm{~mm} \quad(\mathrm{n}=1063)$ and 11.8 (6.40 to 21.6) for patients in the highest suPAR quartile $($ suPAR $>5.35 \mathrm{ng} / \mathrm{ml}, \mathrm{n}=646)$.

Starting ART was associated with an HR of $1.17(0.78$ to 1.76). Adjusted for CD4, MUAC and BMI, the HR for ART became 0.66 (0.42 to 1.03). HIV-1 and doubleinfected patients had an HR of 2.14 (1.19 to 3.85) and 1.92 (0.91 to 4.02), respectively, compared with HIV-2.

\section{Marker sensitivity and specificity: cut-offs leading to the highest combined value}

The optimal combination of sensitivity and specificity to predict mortality within 6 months was obtained at the following cut-offs: CD4 91.8 cells $/ \mu$ l (sensitivity 0.64 and specificity 0.72 ), BMI $18.9 \mathrm{~kg} / \mathrm{m}^{2}$ (sensitivity 0.65 and specificity 0.63 ), MUAC $249 \mathrm{~mm}$ (sensitivity 0.71 and specificity 0.63 ) and suPAR $5.4 \mathrm{ng} / \mathrm{ml}$ (sensitivity 0.71 and specificity 0.76 ).

\section{Evaluation of prognostic markers: MUAC and BMI}

In table 1 are given the results of the assessment of the strengths of the prognostic markers in a situation where suPAR was not available. The analysis included population A with 1054 patients with available MUAC, BMI and CD4 information. It was seen that only $\mathrm{CD} 4 \leq 350$ cells $/ \mu \mathrm{l}$ and MUAC $\leq 250 \mathrm{~mm}$ had significant capacity to predict pre-ART mortality in the multivariate model. A similar result was observed using $\mathrm{CD} 4 \leq 200$ cells/ $\mu$ l instead of CD $4 \leq 350$ cells $/ \mu$ (data not shown). This information suggests that MUAC adds predictive information to the $\mathrm{CD} 4$ cell count. Table 2 further gives the pre-ART predictive capacities of CD4, BMI and MUAC measured by the area under the ROC curve (AUC), where it is observed that MUAC measurement has a capacity close to $\mathrm{CD} 4$ count. 
Table 1 Univariate and multivariate mortality HR from a model without suPAR

\begin{tabular}{|c|c|c|c|c|}
\hline \multirow[b]{2}{*}{ Clinical and laboratory variables } & \multicolumn{2}{|l|}{ Pre-ART } & \multicolumn{2}{|l|}{ Post-ART } \\
\hline & $\begin{array}{l}\text { Unadjusted HR } \\
(95 \% \mathrm{CI})\end{array}$ & $\begin{array}{l}\text { Adjusted HR* } \\
(95 \% \mathrm{Cl})\end{array}$ & $\begin{array}{l}\text { Unadjusted HR } \\
(95 \% \mathrm{Cl})\end{array}$ & $\begin{array}{l}\text { Adjusted HR* } \\
(95 \% \mathrm{Cl})\end{array}$ \\
\hline \multicolumn{5}{|l|}{ Sex } \\
\hline Female & 1 & & 1 & \\
\hline Male & $1.25(0.71$ to 2.19$)$ & & 1.17 (0.63 to 2.18$)$ & \\
\hline \multicolumn{5}{|l|}{ Type of HIV } \\
\hline HIV-2 & 1 & & 1 & \\
\hline HIV-1 & 3.86 (1.50 to 9.93$)$ & & 0.97 (0.43 to 2.17$)$ & \\
\hline Double infected & $2.35(0.70$ to 7.92$)$ & & $1.38(0.50$ to 3.83$)$ & \\
\hline \multicolumn{5}{|l|}{ Baseline CD4 (cells/ $\mu \mathrm{l})$} \\
\hline$\leq 200$ & 13.9 (6.63 to 29.0$)$ & & 1.38 (0.65 to 2.92$)$ & \\
\hline$>200$ & 1 & & 1 & \\
\hline$\leq 350$ & 8.00 (3.16 to 20.3$)$ & 5.96 (2.32 to 15.3$)$ & 0.25 (0.05 to 1.30$)$ & 0.35 (0.07 to 1.85$)$ \\
\hline$>350$ & 1 & 1 & 1 & 1 \\
\hline \multicolumn{5}{|l|}{ BMI $\left(\mathrm{kg} / \mathrm{m}^{2}\right)$} \\
\hline$\leq 18.5$ & $3.33(1.91$ to 5.78$)$ & & 1.95 (1.07 to 3.54$)$ & \\
\hline$>18.5$ & 1 & & 1 & \\
\hline \multicolumn{5}{|l|}{$\operatorname{MUAC}(\mathrm{mm})$} \\
\hline First quartile (116-231) & 15.5 (5.36 to 44.7$)$ & & 5.90 (1.74 to 20.0$)$ & \\
\hline Second quartile (232-255) & 6.86 (2.21 to 21.3$)$ & & 4.29 (1.22 to 15.2$)$ & \\
\hline Third quartile (256-285) & $2.42(0.72$ to 8.12$)$ & & 1.97 (0.50 to 7.79$)$ & \\
\hline Fourth quartile (286-390) & 1 & & 1 & \\
\hline$\leq 250$ & 7.17 (3.71 to 13.9$)$ & 5.60 (2.88 to 10.9$)$ & 3.46 (1.69 to 7.06$)$ & 3.43 (1.68 to 7.02$)$ \\
\hline$>250$ & 1 & 1 & 1 & 1 \\
\hline
\end{tabular}

\section{Prognostic value of suPAR}

In table 3, are provided the results of the assessment of the strength of the prognostic markers in population B with suPAR, MUAC and BMI information available $(\mathrm{n}=628)$. It was observed that only $\mathrm{CD} 4 \leq 350 \mathrm{cells} / \mu \mathrm{l}$ and suPAR had a significant capacity to predict pre-ART mortality in the multivariate model. Table 2 gives the predictive capacities of CD4, BMI, MUAC and suPAR measured by AUC. It is noted that suPAR had the largest

Table 2 Predictive capacity of the different markers: CD4, suPAR, BMI and MUAC measured by area under the ROC curve (with $95 \% \mathrm{Cl}$ )

\begin{tabular}{llll}
\hline Population A & $\mathbf{N}$ & AUC & $\mathbf{9 5 \%} \mathbf{C l}$ \\
\hline CD4 & 1049 & 0.760 & 0.696 to 0.823 \\
BMl & 1049 & 0.699 & 0.628 to 0.771 \\
MUAC & 1049 & 0.747 & 0.681 to 0.813 \\
\hline Population B & $\mathbf{N}$ & AUC & $95 \% \mathbf{C l}$ \\
\hline CD4 & 625 & 0.786 & 0.709 to 0.862 \\
BMI & 625 & 0.667 & 0.569 to 0.765 \\
MUAC & 625 & 0.717 & 0.626 to 0.808 \\
suPAR & 625 & 0.812 & 0.731 to 0.893 \\
\hline AUC,
\end{tabular}

AUC, area under the curve; BMI, body mass index; CD4, CD4 T cell; MUAC, middle-up-arm circumference; ROC, receiver operating characteristic; suPAR, soluble urokinase-type plasminogen activator receptor.
AUC; it was significantly larger than that for BMI $(p=0.02)$ but not for CD4 $(p=0.75)$ and MUAC $(p=0.15)$. ROC curves corresponding to this analysis are illustrated in online supplementary data file 3 .

We further analysed whether baseline suPAR added information on 6-month survival in high-risk patients defined as: patients with $\mathrm{CD} 4 \leq 350$ cells $/ \mu$, $\mathrm{BMI} \leq 18.5 \mathrm{~kg} / \mathrm{m}^{2}$ or MUAC $\leq 250 \mathrm{~mm}$. Mortality was again concentrated in the highest suPAR quartile (figure 1). The HR was respectively, 8.76 (3.44 to 22.3), 8.49 (1.79 to 40.4 ) and 6.76 (2.18 to 21.0$)$ in the three groups.

\section{When CD4 count is not available}

We also assessed if suPAR, MUAC and BMI could help prioritise ART initiation if CD4 is unavailable. We created high-risk groups based on different combinations of the lowest $\mathrm{CD} 4$ quartile $(\mathrm{CD} 4 \leq 92 \mathrm{cells} / \mu \mathrm{l})$, the lowest MUAC quartile (MUAC $\leq 231 \mathrm{~mm}$ ) and the highest suPAR quartile (suPAR $>5.31 \mathrm{ng} / \mathrm{ml}$ ). We compared sensitivity and specificity in these groups to those of $\mathrm{CD} 4 \leq 200 \mathrm{and} \leq 350$ cells $/ \mu \mathrm{l}$. In addition, we present the performance of MUAC $\leq 250 \mathrm{~mm}$ corresponding to situations when no other measures were available. The results in table 4 show that the highest sensitivity was obtained by using both CD4 and suPAR. Adding MUAC just seemed to decrease specificity. Combining CD4 and 
Table 3 Univariate and multivariate mortality HRs from a model with suPAR in population B

\begin{tabular}{|c|c|c|c|c|}
\hline \multirow[b]{2}{*}{ Clinical and laboratory Variables } & \multicolumn{2}{|l|}{ Pre-ART } & \multicolumn{2}{|l|}{ Post-ART } \\
\hline & $\begin{array}{l}\text { Unadjusted HR } \\
(95 \% \mathrm{Cl})\end{array}$ & $\begin{array}{l}\text { Adjusted HR } \\
(95 \% \mathrm{Cl})\end{array}$ & $\begin{array}{l}\text { Unadjusted HR } \\
(95 \% \mathrm{CI})\end{array}$ & $\begin{array}{l}\text { Adjusted HR } \\
(95 \% \mathrm{Cl})\end{array}$ \\
\hline \multicolumn{5}{|l|}{ Sex } \\
\hline Female & 1 & & 1 & \\
\hline Male & 2.07 (0.98 to 4.35$)$ & & 1.31 (0.60 to 2.88$)$ & \\
\hline \multicolumn{5}{|l|}{ Type of HIV } \\
\hline HIV-2 & 1 & & 1 & \\
\hline HIV-1 & $3.61(1.05$ to 12.4$)$ & & 0.81 (0.31 to 2.13$)$ & \\
\hline Double infected & $2.53(0.54$ to 11.8$)$ & & 1.31 (0.38 to 4.49$)$ & \\
\hline \multicolumn{5}{|l|}{ Baseline CD4 (cells/ $\mu \mathrm{l})$} \\
\hline$\leq 200$ & $18.3(6.12$ to 54.7$)$ & & $1.71(0.62$ to 4.67$)$ & \\
\hline$>200$ & 1 & & 1 & \\
\hline$\leq 350$ & 12.6 (2.95 to 53.8$)$ & $5.33(1.15$ to 24.8$)$ & - & - \\
\hline$>350$ & 1 & 1 & 1 & 1 \\
\hline \multicolumn{5}{|l|}{ SuPAR $(n g / m l)$} \\
\hline First quartile (0.22-2.54) & 1 & 1 & 1 & 1 \\
\hline Second quartile (2.54-3.53) & 0.48 (0.04 to 5.62$)$ & 0.45 (0.04 to 5.09$)$ & - & 0.00 \\
\hline Third quartile (3.53-5.31) & $1.89(0.32$ to 11.1$)$ & $1.24(0.20$ to 7.65$)$ & 1.24 (0.29 to 5.29$)$ & $1.29(0.30$ to 5.54$)$ \\
\hline Fourth quartile (5.31-38.7) & 19.0 (4.38 to 82.7$)$ & 10.7 (2.38 to 48.4$)$ & $5.32(1.52$ to 18.7$)$ & $5.09(1.45$ to 17.9$)$ \\
\hline \multicolumn{5}{|l|}{ BMI $\left(\mathrm{kg} / \mathrm{m}^{2}\right)$} \\
\hline$\leq 18.5$ & 2.30 (1.10 to 4.82$)$ & & 1.87 (0.88 to 3.98$)$ & \\
\hline$>18.5$ & 1 & & 1 & \\
\hline \multicolumn{5}{|l|}{ MUAC (mm) } \\
\hline First quartile (116-231) & 19.3 (4.26 to 87.6$)$ & & $5.32(1.16$ to 24.4$)$ & \\
\hline Second quartile (232-261) & 8.24 (1.76 to 38.6$)$ & & 3.85 (0.82 to 18.0$)$ & \\
\hline Third quartile (262-285) & $4.63(0.88$ to 24.5$)$ & & 1.53 (0.24 to 9.62$)$ & \\
\hline Fourth quartile (286-390) & 1 & & 1 & \\
\hline$\leq 250$ & 5.27 (2.34 to 11.9$)$ & & 2.36 (1.01 to 5.55$)$ & \\
\hline$>250$ & 1 & & 1 & \\
\hline
\end{tabular}

suPAR gave higher sensitivity and specificity compared with both $\mathrm{CD} 4 \leq 350$ and $\leq 200$ cells $/ \mu$ l. Combining either CD4 or suPAR with MUAC gave similar specificity but smaller sensitivity compared to CD4 and suPAR. These combinations gave similar sensitivity as CD4 $\leq 200$ cells $/ \mu \mathrm{l}$, but higher specificity. For reference, we observed that a sensitivity of $72 \%$ could be obtained using only MUAC $\leq 250 \mathrm{~mm}$ in situations where nothing else is available.

\section{DISCUSSION}

Our data suggest that BMI, MUAC and suPAR levels are independent risk factors for early mortality in HIV patients in the Bissau-HIV cohort. Other studies in Africa have assessed the short-term prognostic value of nutritional indicators at HIV diagnosis on survival. $^{12} \quad 13 \quad 20 \quad 37$ These studies showed a correlation between a low BMI at enrolment in HIV care and subsequent higher mortality. In studies with CD4 count available, it was also shown that this association was independent of the immune status. ${ }^{12} 13$ In our study, MUAC showed better results than BMI and it was found that an MUAC cut-off of $249 \mathrm{~mm}$ predicted early-mortality with good sensitivity and specificity. The disagreement with previous studies may in part be explained by the fact that BMI was missing in patients too weak to stand in our cohort, and thus, with poor prognosis. Measurement of MUAC only needs minimal resources and does not require sophisticated clinical skills. Moreover, MUAC has the advantage that it can be measured in bedridden patients and does not need further calculations. However, studies using this anthropometric marker in adults are scarce in LMICs. In a previous study done among Ethiopian HIV patients, the MUAC did not have a prognostic value on survival while BMI had. ${ }^{13}$ Nevertheless, due to the good prognostic strength observed in this study and the simplicity of the MUAC measurement, future studies could easily include and test this marker.

With regard to suPAR, studies conducted in pre-ART HIV patients have demonstrated that the circulating levels of this marker are linked to immune activation and independently predict mortality and disease progression. ${ }^{26} 27$ This observation was confirmed in the present study and extended to patients that start ART. 

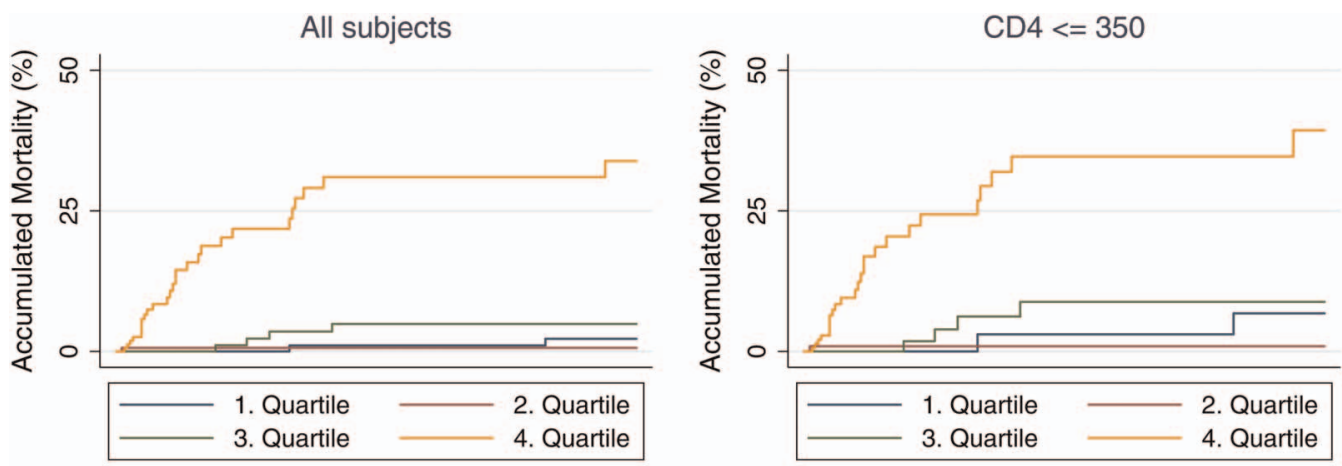

MUAC $<=250$
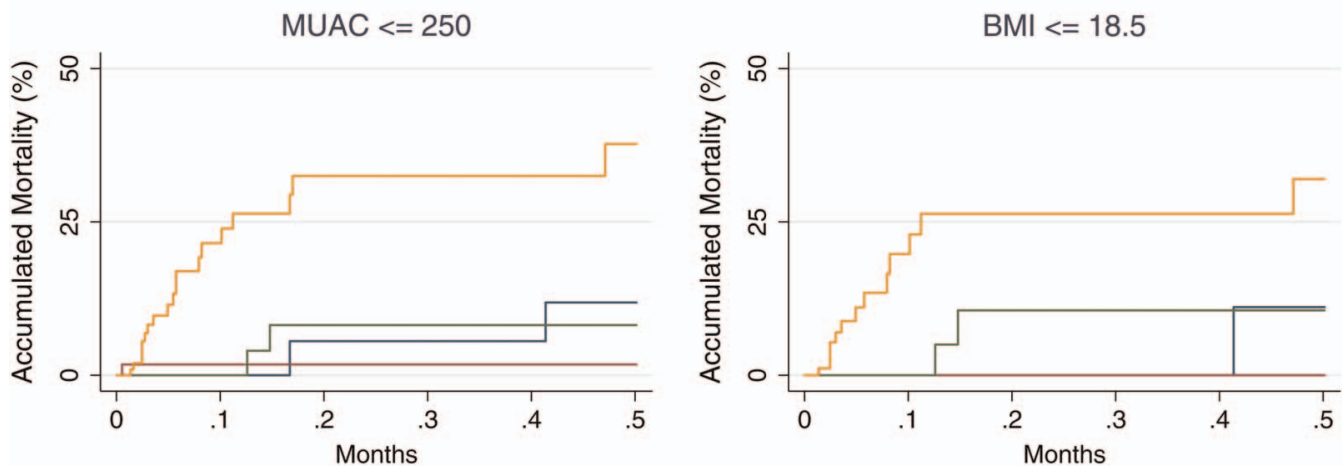

Figure 1 Accumulated mortality by baseline suPAR quartiles for all patients of the cohort, for patients with a low CD4 cell count $(\leq 350 \mathrm{cells} / \mathrm{\mu l})$, for patients with a low MUAC $(\leq 250 \mathrm{~mm})$ and for subjects with a low BMI $\left(\leq 18.5 \mathrm{~kg} / \mathrm{m}^{2}\right)$. The analysis includes the 625 patients contributing with pre-TARV risk time that has all four markers available.

It should be noted that although a high suPAR level at inclusion was still significantly associated with an increased risk of mortality post-ART initiation, the HR post-ART decreased almost fourfold in the highest suPAR quartile (table 3). Thus, initiation of ART reduces the risk of mortality in patients with high inclusion suPAR. Nevertheless, patients with high inclusion suPAR should receive further clinical and diagnostic examination to identify the reasons for an increased risk of mortality.

A recent study by Haupt $e t a l^{88}$ showed that suPAR was strongly correlated to the Charlson Score, with increasing number of comorbidities with increasing suPAR.
While comorbidities or coinfections were not determined in all patients in the present cohort due to limited resources at the time of the study, subsequent studies in the Bissau-HIV cohort have found an HBV coinfection rate of $11.5 \%{ }^{39}$ while antibodies against $\mathrm{HCV}$ (anti-HCV) were positive in $4 \%$ of subjects tested and most frequent among patients $>50$ years. ${ }^{40}$ In this study, no significant difference in death rate was observed between HBV-positive and HBV-negative HIV patients. ${ }^{39}$ With regard to other coinfections, TB is a common disease in Guinea-Bissau, where a community study estimated the incidence of this disease to 471 per

Table 4 Comparing sensitivity and specificity of $C D 4 \leq 200$ cells/ $\mu$ and $C D 4 \leq 350$ cells/ $/ \mu$ to groups consisting of the lowest quartile of CD4 and MUAC and the highest quartile of suPAR

\begin{tabular}{|c|c|c|c|c|}
\hline & Sensitivity & Specificity & $\begin{array}{l}\text { Sensitivity } \\
\text { +specificity }\end{array}$ & $\begin{array}{l}\text { Identified as high risk } \\
\text { should start ART } \\
\text { immediately }\end{array}$ \\
\hline $\mathrm{CD} 4 \leq 92 \mathrm{cells} / \mu \mathrm{l}, \mathrm{MUAC} \leq 231 \mathrm{~mm}$ and $\mathrm{suPAR}>5.31 \mathrm{ng} / \mathrm{ml}$ & 96.9 & 57.5 & 154.4 & $283 / 625(45 \%)$ \\
\hline CD4 $\leq 92$ cells $/ \mu \mathrm{l}$ and suPAR $>5.31 \mathrm{ng} / \mathrm{ml}$ & 96.9 & 65.1 & 162.0 & $238 / 625(38 \%)$ \\
\hline MUAC $\leq 231 \mathrm{~mm}$ and suPAR $>5.31 \mathrm{ng} / \mathrm{ml}$ & 87.5 & 67.1 & 154.6 & $223 / 625(36 \%)$ \\
\hline CD4 $\leq 92$ cells $/ \mu$ l and $M U A C \leq 231 \mathrm{~mm}$ & 87.5 & 65.6 & 153.1 & 232/625 (37\%) \\
\hline $\mathrm{MUAC} \leq 250 \mathrm{~mm}$ & 71.9 & 57.8 & 129.7 & $273 / 625(44 \%)$ \\
\hline CD4 $\leq 200$ cells $/ \mu \mathrm{l}$ & 87.5 & 50.6 & 138.1 & $321 / 625(51 \%)$ \\
\hline CD4 $\leq 350$ cells $/ \mu \mathrm{l}$ & 93.8 & 28.0 & 121.7 & 457/625 (73\%) \\
\hline
\end{tabular}


100000 persons-years. ${ }^{41}$ We have recently shown that an elevated suPAR is associated with an increased risk of mortality for $\mathrm{TB}$ patients on treatment in Guinea-Bissau. ${ }^{42}$ In addition, resent work has shown that suPAR's prognostic value might be related to its ability to display organ dysfunction. ${ }^{43}$ Future studies should register comorbidities, organ biomarkers and test for coinfections to determine whether elevated suPAR is associated with higher prevalence of these conditions. If so, this knowledge could help designing decision trees on tests that can be carried out on HIV-patients with high suPAR levels.

Moreover, our results suggest the plasma level of suPAR in HIV-infected patients adds significant information to that provided by CD4 count. In this study plasma VL was not measured, however previous studies have found only a weak or inexistent relation between SUPAR levels and VL 1524262744 and it was seen that changes in plasma suPAR were independent of changes in VL and CD4 cell count, but were strongly correlated with plasma levels of the soluble tumour necrosis factor receptor II. Therefore, it should be noted that suPAR is not a replacement for VL or CD4 count. SuPAR seems to have a potential as a risk status marker while $\mathrm{VL}$ is a marker of treatment efficacy. Whether suPAR also has potential as a marker of treatment efficacy still remains to be investigated. Thus CD4, VL and suPAR, all add independent information to the prognosis of the patient.

Additionally, our data show that the HR associated with the risk markers decreased following ART enrolment. Opposed to CD4, we observed that BMI, MUAC and suPAR continued to carry prognostic information after ART initiation. This indicates that those patients with a high baseline risk should receive further clinical and diagnostic examination to identify the reasons for increased risk of mortality.

Lastly, according to the new WHO ART guidelines, ${ }^{45}$ ART should be offered to all patients with CD4 count below 350 cells $/ \mu \mathrm{l}$ irrespective of the WHO clinical stage. Lack of health infrastructure or shortness of ARV drugs will hamper the implementation of these guidelines in many developing countries. When many patients access HIV care with advanced HIV infection it is difficult to start treatment to all patients that fulfil ART eligibility. Furthermore, drug shortages have been previously identified as one of the greatest logistic challenge to ART scale-up in subSaharan Africa. ${ }^{46-48}$ In the context of limited resources, prioritising who should start ART first is not a choice, but a practical necessity. In the present study, we observed that MUAC and especially suPAR add prognostic information on early mortality to the CD4 cell count. Also, we observed that none of the 197 patients with suPAR below median and CD4 above 200 died during the follow-up period. Interestingly, patients with low suPAR show very little mortality even in the groups with $\mathrm{CD} 4<350$ cells/ $\mu$ l, or low MUAC or low BMI (figure 1). We are currently investigating whether HIV patients enrolled into ART treatment and characterised as good responders (adherent and CD4>350 cells $/ \mu \mathrm{l}$ ) and with low suPAR can have reduced monitoring thereby reducing costs of the ART programme.

Furthermore, a combination of CD4 and suPAR gave better sensitivity and specificity compared to $\mathrm{CD} 4 \leq 350$ or $\leq 200 \mathrm{cells} / \mu \mathrm{l}$ alone. Using the CD4/suPAR combination, we would reduce the need to start ART immediately to $38 \%$ of the patients compared with $73 \%$ using only the 350 cells/ $\mu$ l CD4 count threshold. This information may have important public health implications in settings with limited resources and ARV drug shortages. Health providers could combine CD4 with suPAR to identify patients in immediate need of treatment when scarce drug resources have to be prioritised. Besides suPAR, a combination of CD4 and MUAC could give the same sensitivity as CD $4 \leq 200$ cells/ $\mu$ l but a better specificity. Actually, this combination could give a sensitivity which is only slightly smaller than CD4 $\leq 350$ cells $/ \mu 1$.

Finally, we observed that suPAR and MUAC carried the same prognostic information as CD4 and MUAC. The combination of suPAR and MUAC gave same sensitivity and higher specificity compared to $\mathrm{CD} 4 \leq$ 200 cells $/ \mu$ l. To summarise, these markers could help identifying patients to whom ART should be prioritised when the CD4 cell count is not available. Finally, we found that MUAC alone can be used as a very simple prioritising tool if nothing else is available.

There are several limitations to this study. First, complete information about risk factors (CD4, suPAR, BMI and MUAC) was only available in 58\% (628/1083) of our population. This was mainly due to lack of suPAR levels that were not measured in $40 \%$ of the patients. The reasons for not having this information available were due to logistic reasons not related to healthcare or mortality, thus we think that it should not affect the general trends presented. Second, WHO-stage, pregnancy status and comorbidities presented at the time of inclusion were not recorded in the database. Furthermore, while a high suPAR was strongly related to mortality, specific causes of mortality were not registered. In a recently published systematic review describing relative causes of early mortality post-ART initiation in different regions, the most common causes of death reported were $\mathrm{TB}$, advanced HIV, wasting, chronic diarrhoea and others. ${ }^{49}$ It is unclear what proportion of wasting in HIV patients could be attributed to TB or other opportunistic infections, but it is likely that TB is playing an important role as described in an autopsy study in South Africa where TB was identified as the most common cause of death in patients on ART. ${ }^{50}$ With the high TB incidence described in Guinea-Bissau, ${ }^{41}$ it is plausible that TB has an important contribution to the mortality in the Bissau-HIV cohort, however only future studies describing causes of death in this setting could help corroborate or reject this hypothesis. Third, contact information for some patients was not sufficient to allow active tracing in case of missed appointments. 
An analysis comparing alive patients versus dead and alive patients versus LTFU subjects showed higher suPAR, lower CD4 and thinness among LTFU than survivors, although not as much as those who we know died (see online supplementary data file 4 ). Thus, it is likely that patients LTFU may include unascertained deaths and that the effects of the risk factors are underestimated in our work.

\section{CONCLUSIONS}

Assessing the nutritional status by measuring MUAC or BMI should be part of the initial clinical evaluation of HIV patients enrolled in HIV care. Our findings suggest that these anthropometrics markers, specifically MUAC, could be helpful in identifying patients with a high risk of dying early. Further studies are needed to evaluate whether nutritional supplements to ART, in these highrisk groups, could be useful for decreasing an early mortality. In case of limited ARV drug resources suPAR plasma levels and MUAC could help health providers to prioritise ART initiation among people with low CD4 count. In situations where CD4 is unavailable or infeasible, suPAR and MUAC could also be used as relatively simple alternatives for ART prioritisation.

\section{Author affiliations}

${ }^{1}$ Bandim Health Project, Indepth Network, Bissau, Guinea-Bissau ${ }^{2}$ Clinical Research Centre, Copenhagen University, Copenhagen, Denmark ${ }^{3}$ National HIV Programme, Ministry of Health, Bissau, Guinea-Bissau ${ }^{4}$ National Public Health Laboratory, Bissau, Guinea-Bissau

${ }^{5}$ Statens Serum Institute, Copenhagen, Denmark

${ }^{6}$ Department of Infectious Diseases, Skejby, Aarhus, University Hospital, Aarhus, Denmark

${ }^{7}$ Centre for Global Health (GloHAU), Institute for Public Health, Aarhus University, Aarhus, Denmark

Acknowledgements We are thankful to all patients for their willingness to participate. Special thanks to the field assistants Augusta, Quintino, Aureliano, Joao and the rest of the staff working in the ART-NSMH for their dedication to work and kindness with patients. We are also grateful to the laboratory staff working in the TB and HIV sections at the National Public Health Laboratory and to the office staff at the Bandim DSS site for making this study possible. The Bissau HIV cohort study group comprises: Amabelia Rodrigues, David da Silva, Zacarias da Silva, Candida Medina, Ines Oliviera-Souto, Lars Østergaard, Alex Laursen, Morten Sodemann, Peter Aaby, Anders Fomsgaard, Christian Erikstrup, Jesper Eugen-OIsen, Christian Wejse (chair).

Contributors The study was planned by $\mathrm{JE}-\mathrm{O}, \mathrm{CW}$ and $\mathrm{IO}$, and executed by I0. AA was responsible for the statistical analyses. PA and ALL were involved in the interpretation of data. CM and DdaS carried out the clinical follow-up of the patients. ZJ daS was responsible for the laboratory HIV test strategies. AF and $I 0$ were responsible for the logistic work in the outpatient ART-SMNH Center. 10 wrote the first draught and all authors contributed to the final version of the paper.

Funding The study was supported by the Bandim Health Project and partially by a grant from the Lundbeck Foundation. The Global Fund to Fight AIDS, TB and Malaria (Global Fund) supported the data collection during 2009-2010 through the 'Secretariado Nacional de Luta contra o Sida' in Guinea-Bissau.

Competing interests Jesper Eugen-Olsen is cofounder and shareholder in ViroGatesA/S, the company that produces the suPARnostic assay. No other authors have any conflict of interest.

Patient Consent Obtained.
Ethics approval National Ethics Committee of Guinea-Bissau.

Provenance and peer review Not commissioned; externally peer reviewed

Data sharing statement Technical appendix, statistical code and dataset are available from the corresponding author at jespereugenolsen@gmail.com. Consent was not obtained by data sharing but the presented data are anonymised and risk of identification is low.

\section{REFERENCES}

1. Egger M, May M, Chene G, et al. Prognosis of HIV-1-infected patients starting highly active antiretroviral therapy: a collaborative analysis of prospective studies. Lancet 2002;360:119-29.

2. Hogg RS, Yip B, Kully C, et al. Improved survival among HIV-infected patients after initiation of triple-drug antiretroviral regimens. CMAJ 1999;160:659-65

3. Palella FJ Jr., Delaney KM, Moorman AC, et al. Declining morbidity and mortality among patients with advanced human immunodeficiency virus infection. HIV Outpatient Study Investigators. N Engl J Med 1998;338:853-60.

4. World Health Organisation (WHO), Joint United Nations Programme on HIV/AIDS (UNAIDS) and United Nations Children Fund (UNICEF),GLOBAL HIV/AIDS RESPONSE-Epidemic update and health sector progress towards Universal Access-Progress Report 2011. Geneva, WHO, UNAIDS, UNICEF. 2011. http://www.unaids. org/en/media/unaids/contentassets/documents/unaidspublication/ 2011/20111130_UA_Report_en.pdf (accessed 12 Jan 2011).

5. World Health Organization (WHO). New progress and guidance on HIV treatment: fact sheet. Geneva, 2010. http://www.who.int/hiv/ vienna2010/en/index.html (accessed 12 Jan 2011).

6. Calmy A, Pinoges L, Szumilin E, et al. Generic fixed-dose combination antiretroviral treatment in resource-poor settings: multicentric observational cohort. AIDS 2006;20:1163-9.

7. Lanoy E, May M, Mocroft A, et al. Prognosis of patients treated with cART from 36 months after initiation, according to current and previous CD4 cell count and plasma HIV-1 RNA measurements. AIDS 2009;23:2199-208.

8. Reus S, Portilla J, Gimeno A, et al. Predictors of progression and death in patients with advanced HIV infection in the era of highly active antiretroviral therapy. Enferm Infecc Microbiol Clin 2004;22:142-9.

9. Braun J, Plantier JC, Hellot MF, et al. A new quantitative HIV load assay based on plasma virion reverse transcriptase activity for the different types, groups and subtypes. AIDS 2003;17:331-6.

10. Gupta RK, Hill A, Sawyer AW, et al. Virological monitoring and resistance to first-line highly active antiretroviral therapy in adults infected with HIV-1 treated under WHO guidelines: a systematic review and meta-analysis. Lancet Infect Dis 2009;9:409-17.

11. Phillips AN, Pillay D, Miners AH, et al. Outcomes from monitoring of patients on antiretroviral therapy in resource-limited settings with viral load, CD4 cell count, or clinical observation alone: a computer simulation model. Lancet 2008;371:1443-51.

12. van der Sande MA, Schim van der Loeff MF, Aveika AA, et al. Body mass index at time of HIV diagnosis: a strong and independent predictor of survival. J Acquir Immune Defic Syndr 2004;37:1288-94.

13. Castetbon K, Anglaret X, Toure S, et al. Prognostic value of cross-sectional anthropometric indices on short-term risk of mortality in human immunodeficiency virus-infected adults in Abidjan, Cote d'Ivoire. Am J Epidemiol 2001;154:75-84.

14. Maas JJ, Dukers N, Krol A, et al. Body mass index course in asymptomatic HIV-infected homosexual men and the predictive value of a decrease of body mass index for progression to AIDS. J Acquir Immune Defic Syndr Hum Retrovirol 1998;19:254-9.

15. Lawn SD, Myer L, Bangani N, et al. Plasma levels of soluble urokinase-type plasminogen activator receptor (suPAR) and early mortality risk among patients enrolling for antiretroviral treatment in South Africa. BMC Infect Dis 2007;7:41.

16. Liechty CA, Solberg P, Were W, et al. Asymptomatic serum cryptococcal antigenemia and early mortality during antiretroviral therapy in rural Uganda. Trop Med Int Health 2007;12:929-35.

17. Lawn SD, Bekker LG, Myer L, et al. Cryptococcocal immune reconstitution disease: a major cause of early mortality in a South African antiretroviral programme. AIDS 2005;19:2050-2.

18. Moh R, Danel C, Messou E, et al. Incidence and determinants of mortality and morbidity following early antiretroviral therapy initiation in HIV-infected adults in West Africa. AIDS 2007;21:2483-91. 
19. WHO. Antiretroviral therapy for HIV infection in adults and adolescents in resource-limited settings: towards an universal access. Geneva: WHO, 2006.

20. Lindan CP, Allen S, Serufilira A, et al. Predictors of mortality among HIV-infected women in Kigali, Rwanda. Ann Intern Med 1992;116:320-8.

21. Thuno M, Macho B, Eugen-Olsen J. suPAR: the molecular crystal ball. Dis Markers 2009;27:157-72.

22. Jaffar S, Van der Loeff MS, Eugen-Olsen J, et al. Immunologica predictors of survival in HIV type 2-infected rural villagers in Guinea-Bissau. AIDS Res Hum Retroviruses 2005;21:560-4.

23. Hazenberg MD, Hamann D, Schuitemaker $\mathrm{H}$, et al. T cell depletion in HIV-1 infection: how CD4+ T cells go out of stock. Nat Immunol 2000;1:285-9.

24. Ostrowski SR, Katzenstein TL, Piironen T, et al. Soluble urokinase receptor levels in plasma during 5 years of highly active antiretroviral therapy in HIV-1-infected patients. J Acquir Immune Defic Syndr 2004;35:337-42.

25. Rosenberg ZF, Fauci AS. Immunopathogenic mechanisms in human immunodeficiency virus (HIV) infections. Ann N Y Acad Sci 1988;546:164-74.

26. Sidenius N, Sier CF, Ullum H, et al. Serum level of soluble urokinase-type plasminogen activator receptor is a strong and independent predictor of survival in human immunodeficiency virus infection. Blood 2000;96:4091-5

27. Ostrowski SR, Piironen T, Hoyer-Hansen G, et al. High plasma levels of intact and cleaved soluble urokinase receptor reflect immune activation and are independent predictors of mortality in HIV-1-infected patients. J Acquir Immune Defic Syndr 2005;39:23-31.

28. Oliveira I, Jensen-Fangel S, da Silva D, et al. Epidemic Stevens-Johnson syndrome in HIV patients in Guinea-Bissau: a side effect of the drug-supply policy? AIDS 2010;24:783-5.

29. UNDP. Human Development Report 2009. Overcoming barriers: Human mobility and development, New York, 2009.

30. United Nations Development Programme (UNDP). Human Development Report 2011.Sustainability and equity: a better future for all. http://hdr.undp.org/en/media/HDR_2011_EN_Summary.pdf. 2011. (accessed 14 Jan 2011).

31. UNAIDS. Suivi de la Déclaration d\&rsquo;engagement sur le VIH/ sida. Guinea-Bissau. Rapport sur la période 2008-2009. Mars 2010. http://www.unaids.org/fr/dataanalysis/monitoringcountryprogress/ 2010progressreportssubmittedbycountries/file,57978,fr..pdf (accessed 27 Mar 2012)

32. Oliveira I, Andersen A, Rasmussen DN, et al. Running before walking: Experiences from the implementation of the HIV Programme in Guinea-Bissau. PhD thesis, University of Copenhagen, 2011.

33. WHO. Scaling up antiretroviral therapy in resource-limited settings guidelines for a public health approach. http://www.who.int/hiv/pub/ prev_care/en/arvrevision2003en.pdf (accessed 14 Jan 2011), 2003.

34. Brinkhof MW, Pujades-Rodriguez M, Egger M. Mortality of patients lost to follow-up in antiretroviral treatment programmes in resource-limited settings: systematic review and meta-analysis. PLoS One 2009;4:e5790.

35. Shetty PS, James WPT. Body mass index - a measure of chronic energy deficiency in adults. FAO Food Nutr Pap 1994;56:1-57.

36. Youden WJ. Index for rating diagnostic tests. Cancer 1950;3:32-5.

37. Zachariah $\mathrm{R}$, Fitzgerald $\mathrm{M}$, Massaquoi $\mathrm{M}$, et al. Risk factors for high early mortality in patients on antiretroviral treatment in a rural district of Malawi. AIDS 2006;20:2355-60.

38. Haupt TH, Petersen J, Ellekilde G, et al. Plasma suPAR levels are associated with mortality, admission time, and Charlson Comorbidity Index in the acutely admitted medical patient: a prospective observational study. Crit Care 2012;16:R130.

39. Honge BL, Jespersen S, Oliveira I, et al. Abstract presentation. Hepatitis B prevalence and mortality among HIV-infected patients in Guinea-Bissau. 28th Annual NSCMID Conference; Reykjavik, 2011.

40. Honge BL. Research year report: Heaptitis prevalence and impact in a West Africa HIV cohort, Aarhus Universitet, 2012.

41. Gustafson P, Gomes VF, Vieira CS, et al. Tuberculosis in Bissau: incidence and risk factors in an urban community in sub-Saharan Africa. Int J Epidemiol 2004;33:163-72.

42. Rabna $\mathrm{P}$, Andersen $\mathrm{A}$, Wejse $\mathrm{C}$, et al. Utility of the plasma level of suPAR in monitoring risk of mortality during TB treatment. PLoS One 2012;7:e43933

43. Zimmermann HW, Koch A, Seidler S, et al. Circulating soluble urokinase plasminogen activator is elevated in patients with chronic liver disease, discriminates stage and aetiology of cirrhosis and predicts prognosis. Liver Int 2012;32:500-9.

44. Ostrowski SR, Katzenstein TL, Pedersen M, et al. Plasma levels of intact and cleaved urokinase receptor decrease in HIV-1-infected patients initiating highly active antiretroviral therapy. Scand $J$ Immunol 2006;63:478-86.

45. WHO. Rapid advice: antiretroviral therapy for HIV infection in adults and adolescents -November 2009 (electronic version). 2009.

46. Weiser S, Wolfe W, Bangsberg D, et al. Barriers to antiretroviral adherence for patients living with HIV infection and AIDS in Botswana. J Acquir Immune Defic Syndr 2003;34:281-8.

47. Elise A, France AM, Louise WM, et al. Assessment of adherence to highly active antiretroviral therapy in a cohort of African HIV-infected children in Abidjan, Cote d'Ivoire. J Acquir Immune Defic Syndr 2005;40:498-500.

48. Laurent C, Meilo H, Guiard-Schmid JB, et al. Antiretroviral therapy in public and private routine health care clinics in Cameroon: lessons from the Douala antiretroviral (DARVIR) initiative. Clin Infect Dis 2005;41:108-11.

49. Gupta A, Nadkarni G, Yang WT, et al. Early mortality in adults initiating antiretroviral therapy (ART) in low-and middle-income countries (LMIC): a systematic review and meta-analysis. PLoS One 2011;6:e28691.

50. Wong EB, Omar T, Sedhako G, et al. Causes of death in ART-treated adults: a post-mortem study from Johannesburg. XVIII International AIDS Conference; Vienna, Austria, 2010. 